\title{
THPO Gene
}

National Cancer Institute

\section{Source}

National Cancer Institute. THPO Gene. NCI Thesaurus. Code C18458.

This gene plays a role in promoting megakaryocytopoiesis, the cellular development process that leads to platelet production. 